\title{
O Município de Cunha: uma proposta de análise geográfica integrada para o ensino. Os aspectos físicos e o histórico de uso e ocupação do solo
}

\author{
The County of Cunha: a proposal for integrated geographic analysis for teaching the \\ physical aspects and the history of land use and occupation
}
El Municipio de Cunha: una propuesta de análisis geográfico integrado para la enseñanza. Los aspectos físicos y el historial de uso y ocupación del suelo

Rosana Silvestre de Lima ${ }^{1}$

\begin{abstract}
RESUMO: Este artigo é resultado da atividade de estudo do meio realizada no município de Cunha em 2016, viabilizada pela disciplina FLG5897 - Ensino e aprendizagem da Geografia e as práticas interdisciplinares em ocasião do curso de pós-graduação em Geografia pela Universidade de São Paulo. Considerando que a análise integrada pode diminuir as distâncias disciplinares entre geografia física e humana, o objetivo deste trabalho é demonstrar essa possibilidade produzindo um intercâmbio das teorias geográficas clássicas como a Tectônica de Placas, a Deriva Continental e a Teoria dos Refúgios com as observações de campo e as informações obtidas no diálogo com a população local e na pesquisa bibliográfica sobre o município. Espera-se com isso favorecer a exploração didática de Cunha para os estudos geográficos integrados.
\end{abstract}

PALAVRAS-CHAVE: Cunha; Vale do Paraíba; Análise integrada; Didática.

ABSTRACT: This article is result of the environmental study activity carried out in the county of Cunha in 2016, within the discipline FLG5897 - Teaching and learning of Geography and interdisciplinary practices in the occasion of the postgraduate course at the University of São Paulo. Whereas the integrated analysis can reduce the disciplinary distances between physical and human geography, the objective of this work is to demonstrate this possibility producing an interchange with classic geographic theories such as Plate Tectonics, Continental Drift and Refuge Theory, with field observations, information obtained through dialogue with stakeholders and bibliographical research about the county. It is hoped, therefore, to favor the didactic exploration of Cunha for integrated geographic studies.

KEYWORDS: Cunha; Paraíba Valley; Integrated analysis; Didatic.

RESUMEN: Este artículo es el resultado de la actividad de estudio del medio realizada en el municipio de Cunha en 2016, viabilizada por la disciplina FLG5897 - Enseñanza y aprendizaje de la Geografía y las prácticas interdisciplinares en el transcurso del curso de postgrado en Geografía por la Universidad de Sao Paulo. Considerando que el análisis integrado puede disminuir las distancias disciplinarias entre geografía física y humana, el objetivo de este trabajo es demostrar esa posibilidad produciendo un intercambio de teorías geográficas clásicas tales como Tectónica de Placas, Deriva Continental y Teoría de los Refugios, con las observaciones de campo y las informaciones obtenidas a través del diálogo con la población local y con la investigación bibliográfica sobre el municipio. Con esto se espera favorecer el aprovechamiento didáctico de Cunha para los estudios geográficos integrado.

PALABRAS-CLAVE: Cunha; Valle del Paraíba; Análisis integrado; Didáctica.

\footnotetext{
${ }^{1}$ Graduada em Geografia. Mestranda em Geografia Física e bolsista CNPQ pelo Departamento de Geografia da Faculdade de Filosofia, Letras e Ciências Humanas, pela Universidade de São Paulo. Avenida Profo Lineu Prestes, 338 - CEP 05508-000 - Cidade Universitária - São Paulo/SP. E-mail: rosana.lima@usp.br.
} 


\section{INTRODUÇÃO}

Cunha é um município localizado no Alto Vale do Paraíba do Sul, no estado de São Paulo. Sua localização estratégica entre o litoral e o interior do país estabeleceu a marca de sua participação no processo histórico de formação do território brasileiro nas várias fases do desenvolvimento econômico: aurífero, cafeeiro e agropecuário. Além disso, seu sítio geomorfológico é visualmente rico em relevo testemunho e sua flora ainda guarda importantes remanescentes de Mata Atlântica que merecem ser devidamente considerados na compreensão dos efeitos paleoclimáticos regionais.

Diante deste contexto, Cunha apresenta potencial didático para os estudos geográficos e ambientais facilitando, aos iniciantes no tema e alunos de geografia, uma percepção integrada através de sua paisagem geográfica. A observação integrada da paisagem pode ajudar a diminuir as distâncias disciplinares colocadas entre geografia física e humana, mas é uma tarefa que exige método, podendo ser facilitada através do estudo do meio e em áreas como Cunha, onde os aspectos físicos não estão totalmente encobertos pelos usos humanos.

De acordo com Pontuschka (2004, p. 260), "o meio é uma geografia viva" e o contato direto com o lugar pode despertar a aprendizagem em seu aspecto dinâmico, o que nos leva a considerar o estudo do meio como método da aprendizagem integrada. A partir desta orientação o objetivo deste artigo é demonstrar como o estudo do meio no município de Cunha pode favorecer a aprendizagem geográfica integrada em diferentes níveis de ensino. A análise integrada que apresentamos neste artigo identifica a relação entre aspectos geográficos físicos e humanos e é resultado direto do estudo do meio realizado por estudantes e professores dentro da disciplina FLG5897 - Ensino e aprendizagem da Geografia e as Práticas Interdisciplinares em ocasião de curso de pós-graduação realizado em 2016.

O estudo do meio é um método de aprendizagem que contempla etapas de organização, realização e produção de resultados. Desta forma, nosso estudo passou por planejamento prévio, definindo local, objetivos da atividade, e os meios práticos de sua realização tais como meio de transporte, trajeto, orçamento, formas de financiamento e a elaboração de um caderno de campo. Já a realização do estudo contou com uma observação sistemática da paisagem a partir das orientações docentes e das entrevistas com a população local. Por último, através das reflexões em grupo e da organização dos materiais coletados foram encaminhadas as pesquisas complementares e a produção de artigos conforme o interesse de assunto dos participantes. 
Este trabalho, enquanto parte dos resultados do estudo do meio realizado, contempla a disposição dialógica com a população, a pesquisa bibliográfica da região e também a análise quanto aos possíveis aproveitamentos didáticos identificados a partir das problematizações estabelecidas na relação entre aspectos geográficos físicos e humanos da realidade investigada.

Ao longo do desenvolvimento apresentamos a localização e o contexto regional em que se insere Cunha, os aspectos geomorfológicos enquanto testemunho para a compreensão da formação dos terrenos paulistas, e a importância hídrica, climática e biodiversa dessa área. Ainda que de forma ampla, referenciamos a estes conteúdos possibilidades de diferentes aproveitamentos didáticos que puderam ser captados em nossa investigação.

\section{A LOCALIZAÇÃO E CONTEXTUALIZAÇÃO DO MUNICÍPIO DE CUNHA - SP}

O município de Cunha localiza-se no extremo leste do estado de São Paulo, estabelecendo limites com Lagoinha e São Luís do Paraitinga, municípios também localizados no Alto Vale do Paraíba do Sul, e com São José do Barreiro, Areias, Silveiras, Lorena e Guaratinguetá, localizados no Médio Vale (MULLER, 1969). No sentido litoral paulista limita-se com Ubatuba e no carioca com Paraty e Angra dos Reis (Figura 1).

Figura 1 - Localização geográfica de Cunha no Vale do Paraíba do Sul - 2016

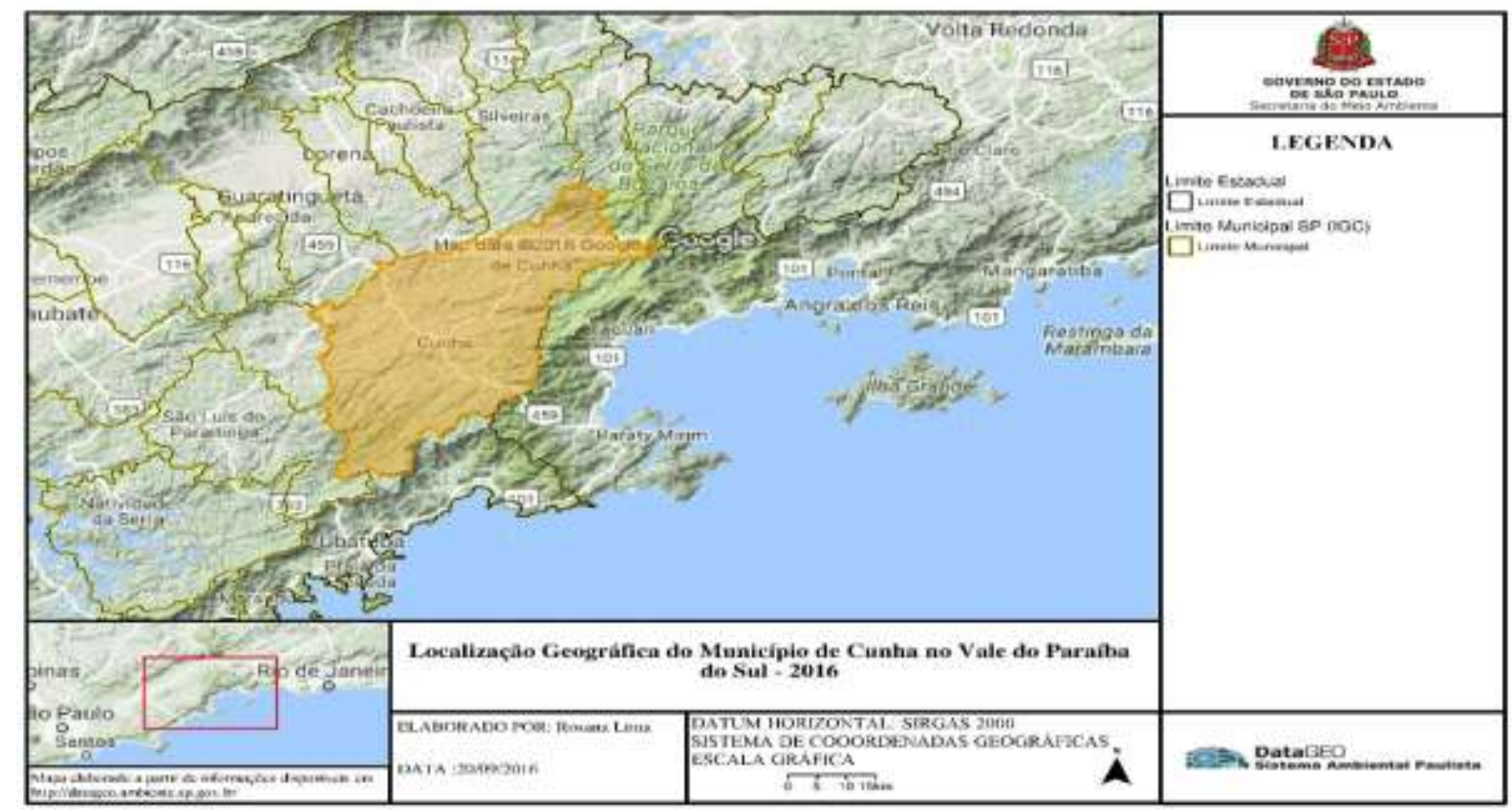

Fonte: do próprio autor com base em São Paulo, 2016a. 
O povoamento desta área e o desenvolvimento do município estão fortemente associados à sua posição geográfica entre o litoral e o interior brasileiro. Os primeiros registros de acesso ao interior brasileiro a partir do litoral carioca, passando por Facão (hoje Cunha), datam do século XVI e destacam a atuação dos povos indígenas Guaianás (Guaianases), importantes tanto na abertura dos caminhos quanto na capacidade de guiar sertanistas com ordens de buscar ouro e prata desde a expedição de Martim Correia de Sá. Oficialmente percorrido, o Caminho da Serra, e também do Ouro, como ficou conhecido devido à sua grande importância no escoamento desse mineral para o litoral, conduziu tropas, tropeiros e comerciantes de forma intensa até a segunda metade do século XVIII, quando novos caminhos foram abertos na região a fim de diminuir os percursos ou ainda despistar corsários. Dessa maneira, o Vale do Paraíba, como é conhecido hoje, foi se desenvolvendo a partir de novas áreas percorridas e do entroncamento de rotas, deixando Cunha em retração no período que praticamente coincidiu com o declínio do ciclo aurífero. É a partir do final do século XVIII e por todo o século XIX que Facão, como era conhecido, retoma sua intensa atividade com o novo aquecimento econômico dado pelo desenvolvimento agrícola e a necessidade de escoamento dos produtos para o litoral, sobretudo o café (VELOSO, 2010).

Estes fatos históricos confirmam o quanto Cunha se estabelece a partir das relações de vizinhança, não podendo desvincular-se do processo mais amplo de ocupação do Vale do Paraíba. Estas relações não somente determinaram acessos viários como também uma tradição comercial regional, marcas que até hoje se fazem presentes na estrutura do município e nos relatos de moradores destacados ao longo deste trabalho. Historicamente, muitas foram as situações de interferências nas rotas, a considerar as posses de terra e a busca por recursos naturais, principais elementos norteadores para criá-las ou mantê-las. Tudo isso foi modificando os percursos, de modo que as estradas atuais que ligam Cunha aos municípios vizinhos em vários pontos não condizem com as aberturas originais, nem mesmo no que se refere ao Caminho do Ouro (VELOSO, 2010), mas representam uma síntese dessa relação regional que se manteve e se tornou tradicional (Figura 2).

Um exemplo atual da continuidade da força dessa relação de vizinhança pode ser observado pela recente reforma estrutural da estrada Cunha-Parati (PAVIMENTAÇÃO..., 2016) que atravessa boa parte do Parque Nacional da Serra da Bocaina, localizado a leste de Cunha, sentido litoral, compreendendo uma reserva de biodiversidade e biomassa. A obra reedita tempos primórdios enquanto mantém a relação comercial respaldada em interesses econômicos, e considera muito pouco os riscos ambientais visíveis do ponto de vista biogeográfico, ainda que hoje sejam mais bem conhecidos e mapeados que no passado. 
Figura 2 - A Ligação Litoral - Interior pela SP- 171 RJ-165

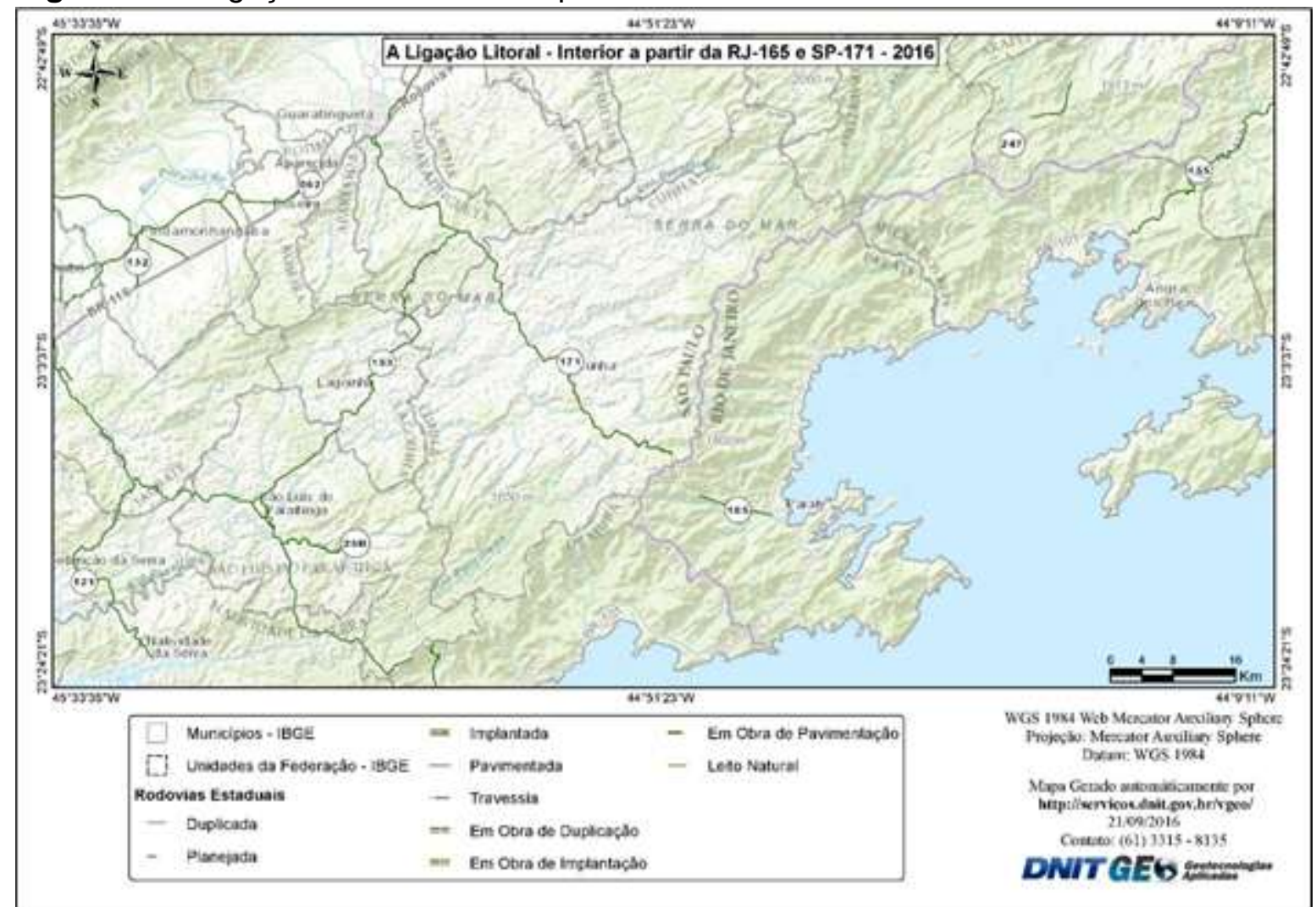

Fonte: do próprio autor a partir de Brasil, 2016.

Apesar de embargos terem paralisado a obra por irregularidades (VIEIRA, 2016), sua execução foi justificada pela diminuição de percurso terrestre entre os estados de São Paulo e Rio de Janeiro e pelo incentivo ao turismo regional. De acordo com matéria publicada em O GLOBO (ARAÚJO, 2013), a obra custou cerca de $\mathrm{R} \$ 85$ milhões, pagos pelo estado do Rio de Janeiro e pela Eletronuclear, sendo esta última interessada na estrada como "rota de fuga" em caso de acidentes nas usinas nucleares de Angra dos Reis (RJ).

Atuando de forma decisiva, os interesses econômicos e o uso intensivo dos recursos naturais na região têm sido constantes de difícil reversão, mesmo em tempos atuais, com a existência de legislações ambientais específicas e áreas protegidas. Ao longo de séculos esse formato de desenvolvimento levou ao esgotamento do solo e redução da Mata Atlântica, além de todos os problemas decorrentes disso, como a diminuição da biodiversidade e da produção e abastecimento de alimentos, a falta de água e o aumento da dependência regional pela crescente discrepância entre recursos naturais e os crescentes aglomerados urbanos.

Ao longo da segunda metade do século $X X$ e atualmente no século $X X I$, a atenção às questões ambientais tomaram dimensões globais, como é sabido e explicitado nos grandes Fóruns Mundiais, a exemplo de Estocolmo (1972), Relatório Brundtland (1987), Eco (1992), 
e Rio+20 (2012) entre outros, mas a capacidade de reversão de processos seculares incutidos no modo produtivo das sociedades ocidentalizadas tem se alterado muito pouco. Isso repercute gravemente nas condições de vida para toda a sociedade, sobretudo em tempos em que a população urbana é crescente. Tanto é que em conjunto às questões ambientais tem se constatado o necessário combate à desigualdade social (UNITED NATIONS MILLENNIUM DECLARATION, 2000) e, portanto, à pobreza, como forma de auxiliar na prevenção à ilegalidade e ao desmantelo no uso dos recursos naturais.

Desalinhada do combate à pobreza e expansão urbana, a especulação imobiliária em Cunha atua de forma intensa, capitalizando áreas verdes que deveriam ser protegidas. De acordo com o corretor da cidade, houve uma queda nas vendas e um aumento no preço das terras devido à abertura da estrada Cunha-Parati (informação verbal concedida durante Estudo do Meio, em Cunha, 13 de maio de 2016), levando-nos a refletir sobre os reais benefícios sociais gerados pelo empreendimento.

O contexto histórico do lugar, identificado pelo estudo do meio, nos permitiu problematizar a relação entre as vantagens espaciais da estrutura física para a ocupação humana do território e suas consequências ambientais. Esta é a abordagem mais ampla da investigação e nela estão contidos todos os conteúdos do trabalho.

Do ponto de vista do aproveitamento didático, esta abordagem pode ser trabalhada nos níveis fundamental e médio a partir da observação da paisagem e do entendimento quanto aos processos de ocupação territorial e seus impactos. Para o ensino superior, o aprofundamento das questões ambientais poderia produzir reflexões quanto ao desenvolvimento sustentável e até gerar pesquisas derivadas como, por exemplo, no aprofundamento quanto à viabilidade técnica da estrada Parati-Cunha.

A seguir avançaremos nos aspectos geomorfológicos, hídricos, climáticos e da biodiversidade do espaço cunhense analisados a partir do estudo do meio e que revelam possibilidades didáticas mais dirigidas dentro da aprendizagem integrada em geografia.

\section{ASPECTOS GEOMORFOLÓGICOS DA REGIÃo DO VALE DO PARAÍBA DO SUL}

O município de Cunha está localizado na área de Planaltos e Serras do Atlântico Leste-Sudeste Brasileiro, dentro da unidade morfoestrutural do Cinturão Orogênico do Atlântico (ROSS; MOROZ, 1997), uma das áreas geomorfológicas mais estudadas do estado de São Paulo, dada sua estrutura heterogênea de formas, com grandes desafios para a ocupação humana, e também por sua relação com os mais recentes movimentos geológicos endogenéticos, mais bem compreendidos com auxílio da teoria da Tectônica de Placas, fortalecida nos anos 1970, após a descoberta da expansão do assoalho oceânico 
por Harry Hass (TASSINARI, 2003) e da Deriva Continental (PENHA, 2007), resultado de pesquisas iniciadas desde o início do século XX por Alfred Wegener (ROSS, 1996).

O contexto de formação da faixa leste do estado de São Paulo dispõe de registros de diferentes processos e tempos geológicos. Nesta área, como já citado, temos o Cinturão Orogênico do Atlântico, formado no Pré-Cambriano há cerca de 2 bilhões de anos com predomínio de rochas ígneas e metamórficas; e também as bacias sedimentares mais litificadas formadas entre o Paleozóico e o Mezosóico iniciadas há cerca de 542 milhões de anos e por fim as bacias sedimentares inconsolidadas do Cenozóico iniciadas há cerca de 65 milhões de anos (ROSS, 1996).

O Cinturão Orogênico do Atlântico, que se estende desde a parte oriental do nordeste brasileiro até o sudeste do estado do Rio Grande do Sul, tem sua origem associada a um processo orogênico pela convergência de placas tectônicas e retrata um conjunto de dobramentos da crosta terrestre na borda do continente de litologia complexa devido às ocorrências de metamorfização, intrusão e efusão vulcânica.

Atividades tectônicas mais recentes iniciadas no Mesozóico e prolongadas até 0 Cenozóico estabeleceram a orogenia andina (dobramentos modernos) no lado oeste do continente e a epirogênese (soerguimentos e abaixamentos) sul americana causando ativação de estruturas falhadas no Cinturão Orogênico Atlântico. Assim, através destes grandes movimentos epirogênicos se formaram a escarpa da Serra do Mar, a Serra da Mantiqueira e a fossa tectônica do Médio Vale do Paraíba do Sul (ROSS, 1996).

Sobre este conjunto de processos geológicos estruturais atuaram forças climáticas intensas em decorrência do período de glaciação do globo durante o Quaternário, no Cenozóico e antes da aparição do homem na Terra. Houve uma expansão dos climas secos em decorrência da estocagem do gelo nos pólos do globo e nos cumes das montanhas e da diminuição do nível do mar e aumento das massas de água fria, com concentração da umidade oceânica e ausência de entrada dos ventos úmidos no interior do continente (AB'SABER, 1992a).

Dadas estas condições, ocorreram mudanças nos processos morfogenéticos e pedogenéticos em paralelo a uma retração da biomassa pré-existente com efeitos para a fauna e flora, assuntos bem desenvolvidos na Teoria dos Refúgios elaborada por Ab'Saber, Haffer e Vanzolini no decorrer da década de 1960 (AB'SABER, 2003).

Todas estas atividades geológicas, climáticas e biológicas associadas produziram diversas paisagens naturais pelo globo. Nos Planaltos e Serras do Atlântico Brasileiro LesteSudeste entre as formas resultantes destes processos estão predominantemente as escarpas, cristas, e morros altos, médios e baixos. Estas formas compõem parte do Alto Vale do Paraíba do Sul, onde localizam-se as bacias hidrográficas do rio Paraibuna e Paraitinga, formadores do Paraíba do Sul. Já as colinas de topo convexo são 
representativas da Depressão, no Médio Vale do Paraíba do Sul. O conjunto revela uma paisagem de morros desgastados cuja mamelonização das vertentes produz a aparência de "mar de morros", assim identificada pelo geógrafo francês Pierre Deffontaines, termo depois amplamente utilizado por Aziz Ab'Saber.

O uso antrópico dos solos na área de Planaltos e Serras do Atlântico Leste-Sudeste e do Domínio de Mar de Morros de forma geral sempre foi uma preocupação do professor e pesquisador Aziz Ab'Saber devido à complexa formação de diferentes pacotes rochosos interpostos combinados à alta declividade, o que aumenta os riscos de intensos processos erosivos, além das dificuldades associadas ao estabelecimento de grandes sítios urbanos e da abertura de estradas. Em entrevista concedida ao Programa RODA VIVA na TV Cultura em 1992, o pesquisador afirmou ambicionar pelos reparos a serem feitos no sudeste brasileiro em função dos ciclos econômicos que seguidamente esgotaram a paisagem natural trazendo graves consequências ambientais e sociais (AB'SABER, 1992b). A destruição das florestas, acentuada na segunda metade do século XVIII com a monocultura e o latifúndio, e depois as rápidas transformações urbanas dadas pela industrialização no século XX, levaram ao empobrecimento dos solos e a decadência da agropecuária regional no Vale do Paraíba do Sul. O contexto ambiental do Vale do Paraíba, e consequentemente do município de Cunha, exige medidas de planejamento com relação às intervenções humanas visando a diminuição de impactos e o aproveitamento sustentável. Esta carência fica ainda mais explicitada pelos frequentes desastres como os ocorridos em São Luís do Paraitinga e Cunha em 2010 e de Teresópolis em 2011 frente às chuvas fortes de verão, propensas de ocorrerem sob o domínio do clima tropical úmido, porém capazes de produzir impactos de elevadas magnitudes devido sua combinação com os diferentes usos humanos.

Os conteúdos geomorfológicos deste item revelam um tipo de resultado do estudo do meio que é o estudo dirigido. As observações sistematizadas da paisagem e a busca por explicações incentivaram pesquisa bibliográfica posterior, alcançando aprofundamentos junto à várias teorias correlacionadas ao tema. Este resultado, em função do elevado aprofundamento, pode ter maior aproveitamento para o nível superior de ensino, mas os conteúdos podem ser considerados também para o ensino médio, principalmente no que se refere ao tectonismo, com exemplos bastante aparentes na paisagem.

\section{AS TRANSFORMAÇÕES ECONÔMICAS E AMBIENTAIS E AS ADAPTAÇÕES DA POPULAÇÃO}

A deterioração ambiental de Cunha mostrou-se perceptível pela população durante o estudo do meio. De acordo com um morador, israelense, que informou estar há 10 anos no 
Brasil e há um ano no município, o solo da região é muito pobre e o plantio requer muito investimento para a recuperação, além das dificuldades em cultivar em terrenos íngremes. Outro aspecto mencionado por ele se refere ao cultivo do eucalipto, crescente na região e que só intensifica o empobrecimento do solo (informação verbal concedida durante Estudo do Meio, em Cunha, 13 de maio de 2016).

O relato de um professor, que é também tradutor, historiador e morador da cidade, confirmou a participação de Cunha nos ciclos econômicos brasileiros, o que se traduz hoje em fortes impactos ambientais. Segundo ele, já no período aurífero predominavam as fazendas de produção no regime de sesmarias com escravos negros. A cidade produzia alimentos para todo o Vale do Paraíba. Depois o novo ciclo do café impôs a retirada da mata original e exposição dos morros, tornando-os mais suscetíveis à processos erosivos e movimentos de massa. Mais recentemente, a pecuária leiteira extensiva também contribuiu para a diminuição da qualidade dos solos em função do pisoteio do gado (informação verbal concedida durante Estudo do Meio, em Cunha, 13 de maio de 2016).

Hoje, a pecuária leiteira está praticamente toda mecanizada na região do Vale do Paraíba por imposições de novas leis voltadas à fiscalização sanitária, o que fez reduzir a atividade de muitos pecuaristas que migraram para outros setores como foi o caso de um dos comerciantes do Mercado Municipal da cidade, filho de pecuaristas que trabalha com a venda de legumes, frutas e verduras. A alteração de atividades rurais para atividades comerciais também pode ser observada sobretudo pelo direcionamento para o turismo, facilmente constatado pela instalação de várias pousadas, ora com aproveitamento de espaços urbanos, ora de espaços rurais.

Os comerciantes com os quais conversamos durante o estudo do meio, tanto no Mercado Municipal quanto na pousada e restaurante rural demonstraram interesse pela aquisição de produtos orgânicos para comercialização e consumo, mas há apenas iniciativas isoladas e particulares com este fim. O município não conta com projeto de revitalização agrícola que possa tratar dos impactos ambientais e oferecer aos pequenos agricultores incentivos para permanecerem atuando no setor.

Por outro lado, embora o município tenha sido afetado em seu equilíbrio natural pelo uso humano das terras, a geomorfologia de Cunha não favorece a extensa ocupação urbana e isso também contribui para um certo isolamento, o que pode explicar em parte a manutenção das características tradicionais da cultura popular, como a religiosidade, o artesanato, a predominância de áreas agrícolas e a ausência de grandes construções e equipamentos urbanos. O mapa da mancha urbana no Vale do Paraíba do Sul demonstra como o desenvolvimento de grandes e médias cidades foram favorecidas pela abertura da Depressão Média do Paraíba do Sul com pouca utilização dos terrenos mais dissecados e de maior altitude (Figura 3), que se verifica em Cunha. 
Figura 3 - Concentração da Mancha Urbana no Médio Vale do Paraíba do Sul

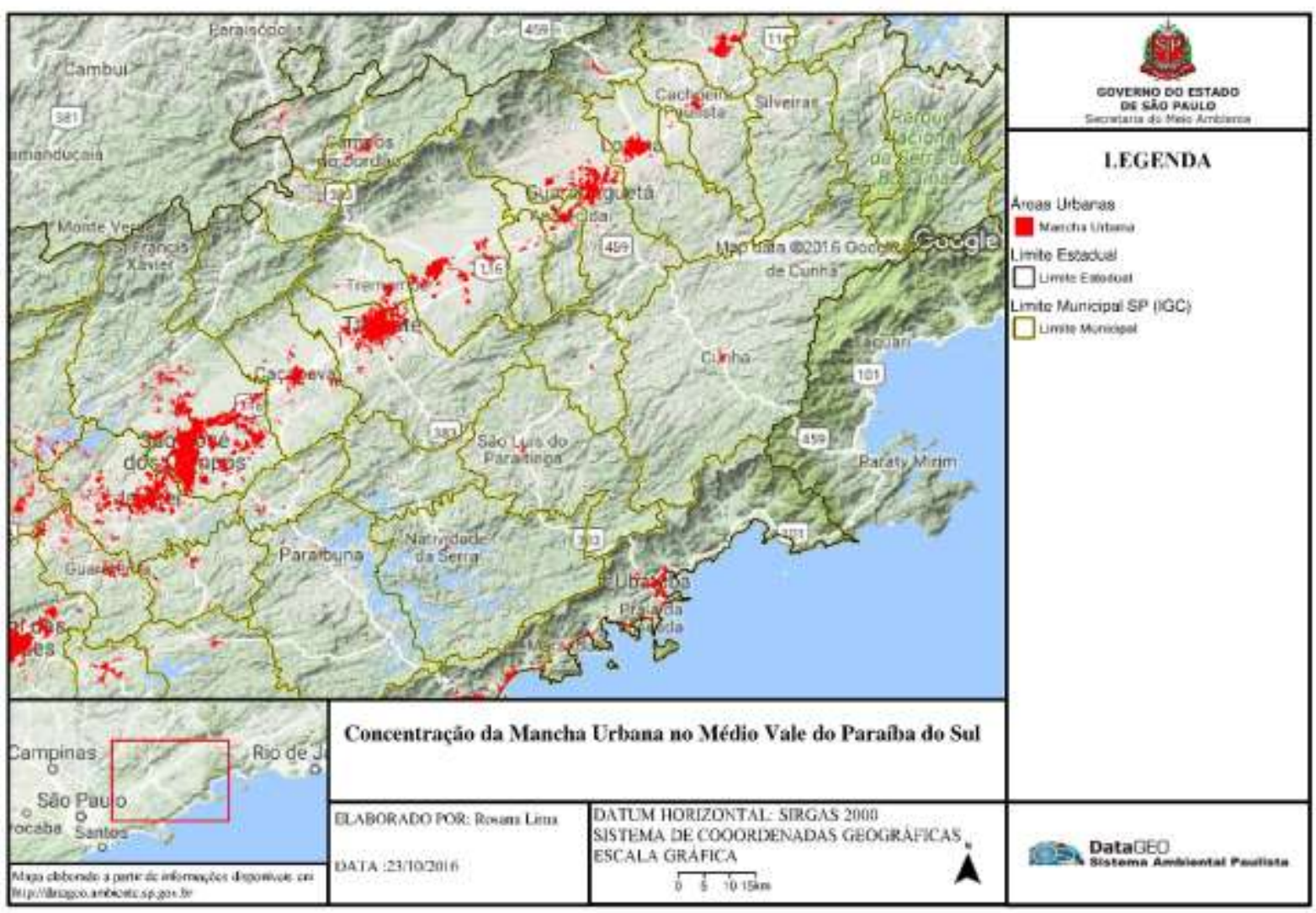

Fonte: do próprio autor a partir de São Paulo, 2016a.

Considerando o todo do lugar, o estudo do meio busca identificar como as questões e conflitos sociais se materializam no espaço, no entanto, quando isso não é visível, as entrevistas junto à população local podem ser reveladoras (PONTUSCHKA, 2004). Neste estudo as entrevistas chamaram a atenção para as mudanças quanto ao perfil de atividades econômicas do município, do rural para o comercial, também sobre o desenvolvimento da silvicultura e a percepção da população quanto à degradação ambiental.

As adaptações da população são, em alguns casos, indicadoras das transformações econômicas que atuam no território e que no caso em estudo envolvem desmatamento, abertura de estradas, ocupação das áreas mais planas para habitação e agricultura, modificação da estrutura dos solos pela pecuária e desenvolvimento do comércio. Esta sequência de ocupação territorial tende a se repetir em muitas paisagens, o que reforça o potencial de Cunha para exploração didática em todos os níveis de ensino. 


\section{ASPECTOS HÍDRICOS: SUA IMPORTÂNCIA E USOS NO VALE DO PARAIIBA DO SUL}

O ciclo hidrológico, muito embora considerado aqui em escala temporal menor que a geomorfológica, também representa fator importante na modificação da paisagem por suas atividades de infiltração, escoamento, precipitação, evaporação, transpiração e percolação da água. A erosão, o arrastamento, o transporte e a deposição de materiais feitos pela água estão associados aos ritmos pluviométricos e fluviométricos. Para isso se estabelece uma estreita relação entre formas, tipos de materiais disponíveis na litosfera e graus de debilidade para a transformação, além dos volumes d'água que atingem o sistema.

No Vale do Paraíba do Sul podemos identificar uma composição de escarpas, morros e colinas com diferentes materiais rochosos interpostos orientando a formação dos cursos d'água. Os falhamentos reativados pela tectônica de placas desde o Cenozóico e a formação do Gráben no Médio Vale do Paraíba influenciam diretamente na formação da rede hidrográfica que passa a constituir-se também como mais um sinalizador geomorfológico da organização da litosfera. O rio Paraíba do Sul está encaixado e adaptado ao Gráben formado pelo processo de epirogênese (ROSS, 1996), por isso em alguns trechos apresenta canal retilíneo, acompanhando o falhamento de rocha homogênea que se mantém assim por oferecer o mesmo tipo de resistência diante da ação das águas.

A condição do relevo propicia também maior escoamento da água e grande impacto erosivo, como nos explica Almeida (1974, p. 26-27) a respeito do Planalto do Paraitinga, dentro do Planalto Atlântico:

Trata-se de um planalto cristalino, de estrutura complexa, maturamente dissecado, com relevo de "mar de morros" e longas serras longitudinais [...]. Nas depressões aloja-se rede de drenagem acentuadamente diversificada, desenvolvida em vales estreitos, sem planícies aluviais [...], com baixos terraços marginais, interrompidos onde os vales se estreitam e os rios se precipitam em rápidos e cachoeiras. Do município de Cunha ao cotovelo de Guararema as águas do Paraitinga, rio que nasce a uns $2000 \mathrm{~m}$ de altitude na Bocaina, e as do rio Paraíba descem pouco mais de $200 \mathrm{~m}$, num trecho que em reta mal atinge $120 \mathrm{~km}$, declividade que é ainda ultrapassada pelo rio Paraibuna. Disso decorre o vigor erosivo desses cursos de clima úmido, explicando o caráter apertado de seus vales e os numerosos acidentes fluviais $[\ldots]$

Já a carga de água recebida através do ritmo pluviométrico tem a interferência do oceano Atlântico, da Frente Polar e dos processos orográficos devido à variada altimetria do relevo estabelecendo também diferentes volumes de precipitações, a considerar os maiores índices nas regiões mais altas, atingindo entre 1300 a 2800 milímetros ao ano na Serra do Mar e Serra da Mantiqueira (SOARES et al., 2008). 
Os cursos hídricos no Vale estão representados pela bacia hidrográfica do rio Paraíba do Sul que atinge os estados de São Paulo, Minas Gerais e Rio de Janeiro. Em São Paulo, no Alto Vale, os principais rios são o Paraitinga e o Paraibuna que nascem e confluem para a formação do rio Paraíba do Sul em Guararema, à oeste, redirecionando o curso d'água que segue pelos estados de Minas Gerais e Rio de Janeiro (Figura 4).

Figura 4 - Bacia Hidrográfica do Rio Paraíba do Sul

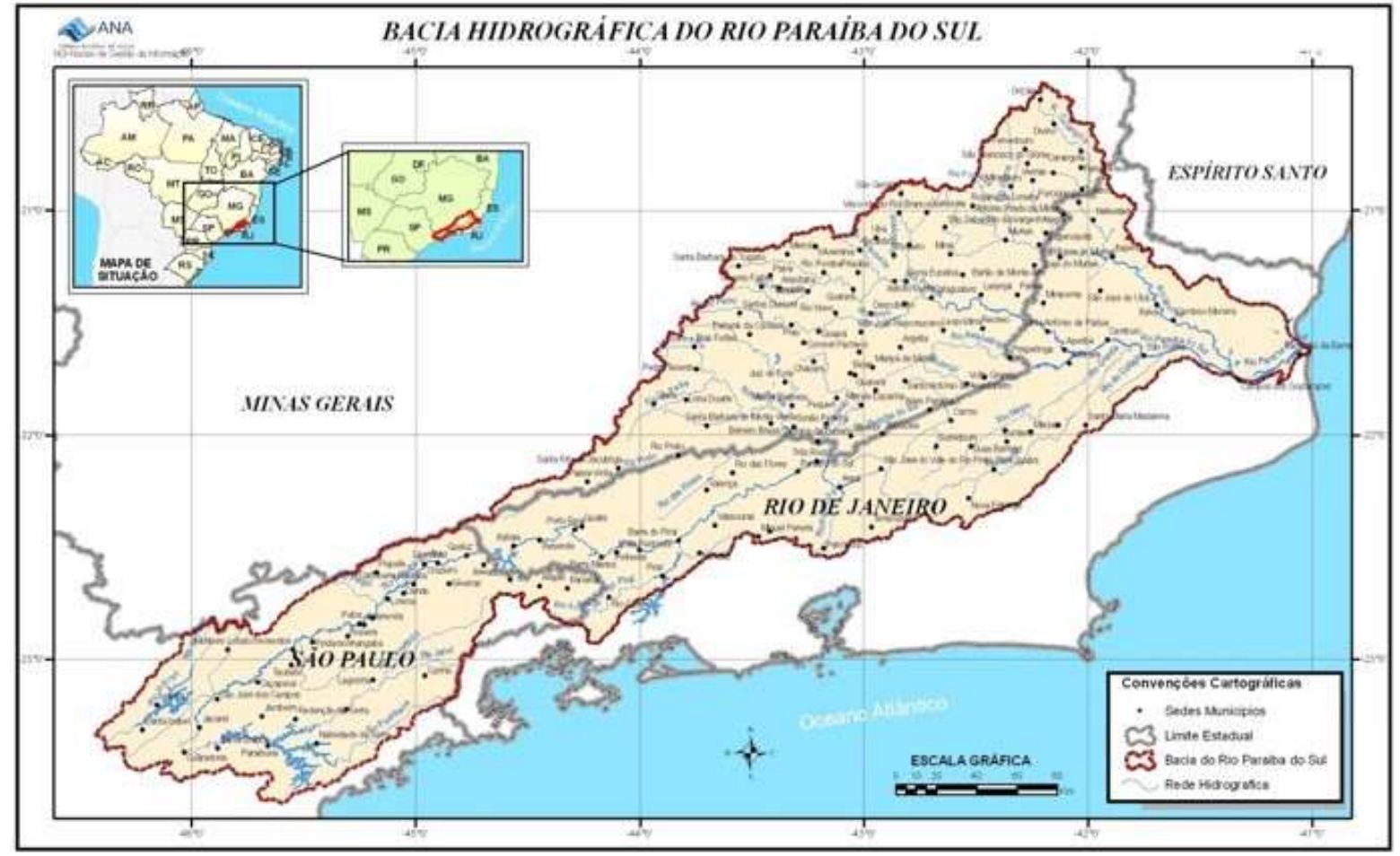

Fonte: Agência Nacional de Águas (2016b).

Essa formação revela uma característica das mais interessantes do mundo, entendida como anomalia hidrográfica (AB'SABER, 1998) que trata da hipótese de captação de um curso d'água da Bacia do Tietê para a formação do que se chama hoje "Cotovelo de Guararema". De acordo com Pasa (2013) as variações climáticas do Quaternário junto a fatores geológicos teriam interferido no sistema de drenagem favorecendo a captura pelo Paraibuna de águas que fluiriam para o Tietê. Converge para esta hipótese o fato de que existe um vale seco entre o "Cotovelo de Guararema" e a bacia do Tietê (Figura 5).

Ademais de toda a importância paleogeográfica da bacia do Paraíba do Sul, sua dimensão e potencial como recurso natural são de grande valor histórico no desenvolvimento econômico da região sudeste brasileira provendo, ainda hoje, energia e abastecimento de água para a população do entorno, para a indústria e agropecuária. A disputa e os conflitos existentes entre os estados pelos quais o rio atravessa reforça este aspecto, com reivindicações do Rio de Janeiro sobre maior proteção das águas à montante 
em função da sua condição de aproveitamento das águas no Baixo Vale, que deveriam chegar com melhor qualidade, e também por São Paulo que pretende realizar uma obra de interligação para o sistema Cantareira (INTERLIGAÇÃO..., 2016) de abastecimento. Mas já são notórios o assoreamento e a poluição de origem doméstica no rio (ROSSETTI, 2009), o que compromete a continuidade do provimento destes recursos para toda a sociedade devido ao uso intensivo e sem os cuidados ambientais necessários.

Figura 5 - Localização do Vale Seco em relação às duas bacias hidrográficas

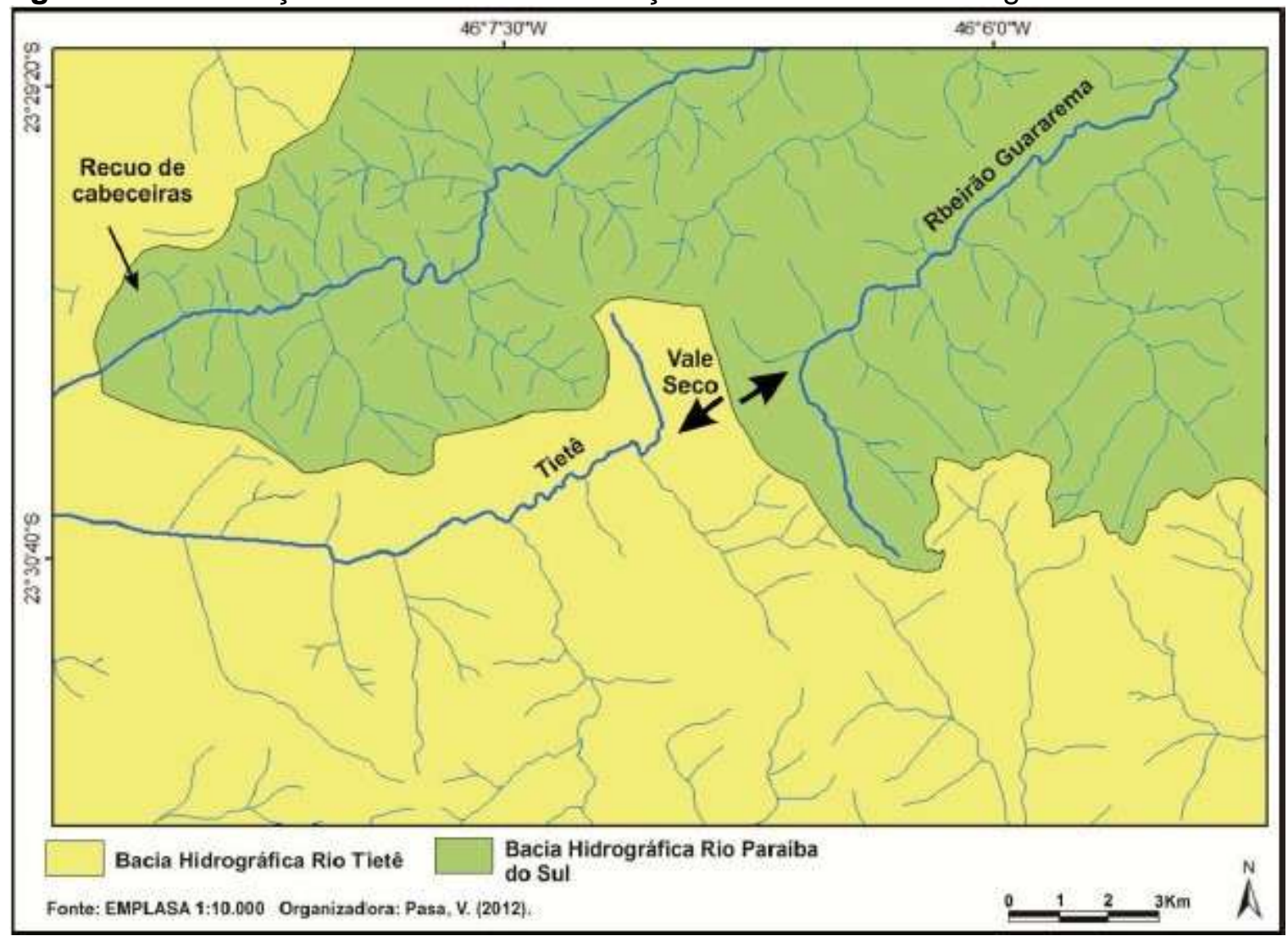

Fonte: Pasa (2013, p. 58).

Acrescentamos a este quadro o problema da falta de água na região sudeste brasileira mais crítico em tempos atuais, tanto em decorrência do desmantelamento do funcionamento natural da paisagem quanto pela gestão precária e aumento da pressão e demanda dos centros urbanos pelo uso dos recursos naturais. Para o município de Cunha, a situação é agravada pela dificuldade de captação em quantidade suficiente para suprir o abastecimento, problema historicamente narrado por Veloso (2010). Mesmo diante de toda riqueza hídrica regional e do desenvolvimento técnico atualmente conhecido, ainda há dificuldades no abastecimento de água. A última seca que atingiu o estado de São Paulo em 2014 chegou também ao município revelando ausência de investimentos no setor. De acordo com dados da Agência Nacional de Águas (2016a) o abastecimento da cidade é feito integralmente por captação em manancial na Cachoeira do Pimenta, sendo a rede hídrica 
como um todo pouco explicitada quanto a sua utilização. Outros aspectos que dizem respeito ao saneamento básico e nível de poluição dos cursos d'água não são demonstrados pela Agência.

A água é um recurso natural reconhecidamente necessário em diversas atividades econômicas e para a vida humana de forma ampla. Isso faz com que o tema seja amplamente explorado tanto no ensino como nos veículos midiáticos. No entanto, as observações em Cunha tornaram aparentes contradições entre abundância hídrica e falta de abastecimento, alcançando o problema da gestão do recurso e, portanto, ultrapassando os conhecimentos restritos ao ciclo hidrológico. Também podemos afirmar que as várias correlações com teorias paleogeográficas, estabelecidas pelo estudo dirigido, encaminharam aprofundamentos para a análise integrada entre clima, geomorfologia e hidrologia no entendimento do contexto geográfico de Cunha. Estes aproveitamentos do estudo podem alcançar interesses didáticos tanto para os níveis fundamental e médio como superior de ensino.

\section{A RELEVÂNCIA CLIMÁTICA E BIODIVERSA DE CUNHA: OS REMANESCENTES DE MATA ATLÂNTICA}

O clima de Cunha sempre exerceu influência na fixação de povoados. Durante os séculos XVII e XVIII os europeus encantaram-se com o clima de temperaturas amenas, o solo fértil, a beleza paisagística do lugar e as águas límpidas. Houve também uma identificação com os climas conhecidos na Europa o que facilitou a instalação destes povos na região. Além disso, a partir da segunda metade do século XIX se estabelece uma relação entre o clima e a melhora de pacientes que sofriam de problemas pulmonares fazendo com que o Barão da Bocaina quisesse construir na região uma estação climatéria. Esse ideal não se concluiu, mas após décadas de reivindicações de lideranças regionais o município foi qualificado como Estância Climática, em 1948 (VELOSO, 2010).

As características climáticas de Cunha podem ser entendidas pela dinâmica atmosférica controlada pela célula de Alta Pressão Subtropical do Atlântico Sul (Massa Tropical Marítima) e também pelas interferências da Massa Tropical Continental e da Frente Polar. O clima do município pode ser identificado como Tropical de Altitude, característico dentro do domínio Tropical em regiões com altitude superior a 1.000 metros (CONTI; FURLAN, 1996).

Este jogo de massas de ar junto às condições do relevo e altitudes elevadas são os principais elementos que definem a distribuição de chuvas, gerando, de forma sintética, duas estações do ano, o inverno mais seco com a menor penetração do ar polar, e o verão 
úmido com aumento de precipitações devido principalmente ao eixo reflexo da Frente Polar. As temperaturas médias no verão podem ficar entre $23^{\circ}$ e $19^{\circ}$ e no inverno entre $17^{\circ}$ e $14^{\circ}$ (ARMANI, 2004).

Em condições de maior penetração de ar frio as baixas temperaturas podem provocar as conhecidas geadas com efeitos negativos para as lavouras. Já no verão, os riscos estão relacionados aos movimentos de massas. Chuvas intensas, combinadas às condições do relevo dissecado e entalhado por bacias hidrográficas e ao tipo de ocupação humana, podem levar a eventos catastróficos como o ocorrido em 2010 quando os escorregamentos levaram a mortes por soterramento e à destruição de centenas de bens públicos e particulares (GASPARIN, 2010).

O município, situado a 1.500 metros acima do nível do mar (SÃO PAULO, 2016b) exerce um importante papel ecossistêmico, o que Ihe rendeu, em sua porção sul, medidas de proteção com a instalação do núcleo que integra parte do Parque Estadual da Serra do Mar, criado em 1977. De acordo com a Fundação Florestal, esta região contém uma das porções de maior biodiversidade de todo o parque. O destaque da flora é a espécie Araucaria angustifólia, o "Pinheiro brasileiro", marca registrada do município e que ajuda a promover a Festa do Pinhão anualmente. Esta espécie está ameaçada de extinção e tem no núcleo Cunha uma grande área de preservação (SÃO PAULO, 2016b).

Estima-se que esta espécie, bem adaptada a climas mais amenos e secos, possua 200 milhões de anos, fazendo-se presente antes dos períodos pleistocênicos (ANGELI, 2017). Assim, a Araucária pode ser considerada como um "fóssil vivo", contendo importantes informações da formação florística da Mata Atlântica no Domínio de Mar de Morros. De acordo com a Teoria dos Refúgios, os efeitos climáticos da última glaciação no Pleistoceno teriam feito restringir a fauna e a flora em benefício daquelas que melhor se adaptaram ao clima seco provocando processos evolutivos complexos nas espécies (AB'SABER, 1992a). A existência de uma variedade de Araucárias, efeito de diferentes processos de especiação, e a ocorrência disjunta em áreas tropicais e subtropicais pluviais (ANGELI, 2017), pode ser considerada como uma das evidências das grandes teorias paleogeográficas, como a de retração pleistocênica e de reintegração da tropicalidade (AB'SABER, 1992a).

A compreensão paleogeográfica na formação das paisagens, tão caras à sobrevivência humana e à apropriação dos recursos, se faz necessária para alcançar provisionamentos de longo prazo, inclusive a considerar escala de 10 a 20 mil anos (AB'SABER, 1992a), quando poderá haver novos períodos secos no globo a encontrar as grandes aglomerações de cidades e a escassa biodiversidade configurando imensos riscos às sociedades humanas. 
A retirada da Mata Atlântica, em sua extensão azonal, que compreende diferenças morfológicas e topográficas reconhecidas para a biodiversidade, tem se tornado uma preocupação ambiental global, reconhecendo neste bioma uma área chave de preservação para o planeta, um hotspot mundial. Estima-se que em sua composição original a Mata Atlântica abrangia cerca de um milhão de metros quadrados, restando hoje apenas $8,5 \%$ da porção original (FUNDAÇÃO SOS MATA ATLÂNTICA, 2017) confirmando um quadro de ameaça a este ambiente. Ao processo secular de devastação acrescenta-se o problema do reflorestamento e a substituição de espécies do ecossistema pelo eucalipto.

O plantio do eucalipto como monocultura para exploração da madeira se reflete na fertilidade dos solos que tem relação com o acúmulo da serrapilheira. O curto prazo entre o plantio e o corte da madeira não permite as condições adequadas para a formação dos solos. Além disso, as grandes concentrações da espécie limitam a biodiversidade e a formação de corredores ecológicos. O Vale do Paraíba tem sido uma área fortemente afetada pela expansão do cultivo de eucaliptos desde os anos 1960, como nos revela estudos realizados por Freitas Junior (2011). No levantamento em que considera 15 municípios valparaibanos, seis possuem área de mata remanescente inferior a 10\% de seu território, o que já demonstra um risco ambiental na região. Além disso, 10 entre os 15 apresentam áreas ocupadas com eucalipto em percentual superior àquelas cobertas por vegetação original, em diversos níveis topográficos, sem um zoneamento que regularize essa atividade.

Durante o estudo do meio no município de Cunha o eucalipto pôde ser observado tanto na paisagem como nos ateliês de cerâmica de alta temperatura, que utilizam a madeira para aquecimento dos fornos. A incorporação do produto na economia local demonstra mais um desafio para o controle e recuperação do bioma de Mata Atlântica.

A observação florística na paisagem de Cunha abriu possibilidades para a compreensão das atividades econômicas associadas à silvicultura e ao pinhão, aos impactos ambientais em relação ao bioma original e à relação de dependência entre clima e vegetação. Os aproveitamentos didáticos para os níveis fundamentais e médio de ensino podem tratar da caracterização florística, destacando as características dos Domínios Morfoclimáticos de Mares de Morros e das Araucárias, bem como da degradação do bioma de Mata Atlântica. Para o ensino superior podem ser destacados os estudos dirigidos com enfoque na pesquisa biogeográfica. 


\section{CONSIDERAÇÕES FINAIS}

O estudo do meio realizado no município de Cunha permitiu avançar em conhecimentos geográficos de maneira aprofundada, tanto em função dos indicadores para a análise que surgiram junto às entrevistas com a população local quanto por sua localização dentro do Vale do Paraíba, área que reúne atributos geográficos tratados de forma extensa por estudiosos brasileiros e estrangeiros evidenciando importantes conceitos e teorias na formação da paisagem geográfica.

Entre as teorias tratadas neste trabalho, podemos citar a da Tectônica de Placas e da Deriva Continental que possibilitaram a compreensão das condições estruturais do relevo e suas principais fragilidades associadas às condições de clima e ocupação humana. Também a Teoria dos Refúgios pôde ser explorada, destacando sua importância em estudos científicos de fenômenos de curta e longa duração a considerar os ciclos climáticos do planeta e a consequente importância do planejamento territorial.

A metodologia desenvolvida com o estudo do meio ofereceu a possibilidade de se construir um eixo integrador para a análise espacial geográfica a partir de uma realidade local, portanto adaptada ao contexto de estudo, criando um currículo próprio. De tal forma, o estudo apresentado não pretende delimitar formas de exploração didática para o município de Cunha, mas demonstrar algumas possibilidades de associações entre os usos humanos dos recursos naturais e seus efeitos ambientais através dos aspectos identificados na paisagem e no contexto social, evidenciados pela análise integrada.

Espera-se que o resultado deste trabalho possa inspirar práticas de abordagem integrada, a fomentação da região de estudo como sugestão para a aprendizagem geográfica e a discussão de temas ambientais a partir dos conhecimentos geográficos, tão preciosos para as práticas de ensino contemporâneas.

\section{REFERÊNCIAS}

AB'SABER, A. N. A teoria dos refúgios: origem e significado. In: CONGRESSO NACIONAL DE ESSÊNCIAS NATIVAS, 2., 1992, São Paulo. Anais... São Paulo: Instituto Florestal, 1992a. p. 29-34.

ECO 92: biodiversidade e possíveis fontes renováveis de energia. Entrevista concedida ao Programa Roda Viva. São Paulo: TV Cultura, 1992b. Disponível em: <https://www.youtube.com/watch?v=QEYqoH4sZ5I>. Acesso em: 27 maio 2018.

Megageomorfologia do território brasileiro. In: CUNHA, S. B; GUERRA, A. J. T. (Org.) Geomorfologia do Brasil. São Paulo: Bertrand Brasil, 1998. p. 71-106. Ateliê, 2003.

Os domínios de natureza no Brasil: potencialidades paisagísticas. São Paulo: 
AGÊNCIA NACIONAL DE ÁGUAS - ANA. Atlas Brasil. Abastecimento urbano de água. 2016a. Disponível em: <http://atlas.ana.gov.br/Atlas/forms/analise/Geral.aspx?est=6>. Acesso em: 14 jun. 2016.

Bacia hidrográfica do Rio Paraíba do Sul. 2016b. Disponível em: <http://arquivos.ana.gov.br/institucional/sag/CobrancaUso/BaciaPBS/_img/MapaPBS.jpg>. Acesso em: 6 jul. 2016.

ALMEIDA, F. F. M. Fundamentos geológicos do relevo paulista. São Paulo: Instituto de Geografia da USP, 1974. (Série Teses e Monografias, 14).

ANGELI, A. Araucaria angustifólia (Araucaria). Piracicaba: Instituto de Pesquisas e Estudos Florestais -IPEF, $2017 . \quad$ Disponível em: <http://www.ipef.br/identificacao/araucaria.angustifolia.asp>. Acesso em: 5 jul. 2017.

ARAÚJO, P. R. Após 25 anos de embargos ambientais, estrada-parque entre Paraty e Cunha é pavimentada. 0 Globo, Rio de Janeiro, 2 dez. 2013. Disponível em: <http://oglobo.globo.com/rio/apos-25-anos-de-embargos-ambientais-estrada-parque-entreparaty-cunha-pavimentada-10938752 . Acesso em: 13 jun. 2016.

ARMANI, G. Interações entre a atmosfera e a superfície terrestre: variações da temperatura e umidade na bacia B do Núcleo Cunha (IF) - SP. 2004. Dissertação (Mestrado em Geografia) - Universidade de São Paulo, São Paulo. Disponível em: <http://www.teses.usp.br/teses/disponiveis/8/8135/tde-11122013-112544/pt-br.php>. Acesso em: 5 jul. 2017.

BRASIL. Departamento Nacional de Infraestrutura de Transportes - DNIT. Geotecnologias Aplicadas. Disponível em: <http://servicos.dnit.gov.br/vgeo/>. Acesso em: 21 set. 2016.

CONTI, J. B.; FURLAN, S. A. Geoecologia: o clima, os solos e a biota. In: ROSS, J. L. S. (Org.). Geografia do Brasil. São Paulo: EDUSP, 1996. p. 162 - 172.

FREITAS JUNIOR, G. O eucalipto no Vale do Paraíba Paulista: aspectos geográficos e históricos. Dissertação (Mestrado em Geografia). 2011. São Paulo. Disponível em: <http://www.teses.usp.br/teses/disponiveis/8/8135/tde-26062012-140626/pt-br.php>. Acesso em: 5 jul. 2017.

FUNDAÇÃO SOS MATA ATLÂNTICA. Florestas: Mata Atlântica. São Paulo, 2017. Disponível em: <https://www.sosma.org.br/nossa-causa/a-mata-atlantica>. Acesso em: 5 jul. 2017.

GASPARIN, G. Família morta em soterramento em Cunha é enterrada na capital paulista. G1, São Paulo, 3 jan. 2010. Notícias. Disponível em: <http://g1.globo.com/Noticias/SaoPaulo/0,,MUL1433245-5605,00-

FAMILIA+MORTA+EM+SOTERRAMENTO+EM+CUNHA+E+ENTERRADA+NA+CAPITAL+ PAULISTA.html.>. Acesso em: 4 jul. 2017.

INTERLIGAÇÃO do rio Paraíba do Sul com o Cantareira recebe aval ambiental. Folha de São Paulo, São Paulo, 22 jan. 2016. Cotidiano. Disponível em: <http://www1 folha.uol.com.br/cotidiano/2016/01/1732488-interligacao-do-rio-paraiba-do-sulcom-o-cantareira-recebe-aval-ambiental.shtml>. Acesso em: 6 jul. 2017.

MULLER, N. L. O fato urbano na Bacia do Rio Paraíba - São Paulo. Rio de Janeiro: Fundação IBGE, Divisão Cultural, 1969.

PASA, V. Estudo da conexão entre as drenagens do Médio Paraíba do Sul e do Alto Tietê: o caso do Cotovelo de Guararema - SP/ Brasil. 2013. Dissertação (Mestrado em Geografia) - Universidade de São Paulo, São Paulo. Disponível em: <http://www.teses.usp.br/teses/disponiveis/8/8135/tde-23102013-125132/pt-br.php>. Acesso em: 13 jun. 2016. 
PAVIMENTAÇÃO é concluída e estrada Cunha-Paraty reabre ao tráfico. Folha de São Paulo, São Paulo, 6 jul. 2016. Turismo. Disponível em: <http://www1.folha.uol.com.br/turismo/2016/07/1788981-pavimentacao-e-concluida-eestrada-cunha-paraty-reabre-ao-trafego.shtml>. Acesso em: 6 jul. 2017.

PENHA, H. M. Processos endogenéticos na formação do relevo. In: GUERRA, A. J. T.; CUNHA, S. B. (Org.). Geomorfologia: uma atualização de bases e conceitos. Rio de Janeiro: Bertrand, 2007. p. 51-92.

PONTUSCHKA, N. N. O conceito de estudo de meio transforma-se ... em tempos diferentes, em escolas diferentes, com professores diferentes. In: VESENTINI, J. W. (Org.). O ensino de geografia no século XXI. Campinas: Papirus, 2004. p. 249-268.

ROSS, J. L. S. Os fundamentos da geografia da natureza. In: ROSS, J. L. S. (Org.). Geografia do Brasil. São Paulo: EDUSP, 1996. p. 13-65.

ROSS, J. L. S.; MOROZ, I. C. Mapa geomorfológico do Estado de São Paulo. São Paulo: Laboratório de Geomorfologia, Departamento de Geografia, 1997.

ROSSETTI, R. P. Evolução da carga orgânica de origem doméstica no rio Paraíba do Sul, no trecho paulista, no período de 1998-2007. 2009. Dissertação (Mestrado em Geografia Física) - Universidade de São Paulo, São Paulo. Disponível em: <http://www.teses.usp.br/teses/disponiveis/8/8135/tde-01022010-162610/pt-br.php>. Acesso em: 5 jul. 2017.

SÃO PAULO. Secretaria do Meio Ambiente. Fundação Florestal. Parque Estadual da Serra do Mar. Núcleo Cunha. Sobre o núcleo. São Paulo, 2016b. Disponível em: <http://www.parqueestadualserradomar.sp.gov.br/pesm/nucleos/cunha/sobre/>. Acesso em: 15 jun. 2016.

SÃO PAULO. Sistema Ambiental Paulista. DATAGEO. Infraestrutura de Dados Espaciais Ambientais - 2016 . IDEA. Disponível <http://datageo.ambiente.sp.gov.br/web/guest/inicio>. Acesso em: 13 jun. 2016.

SOARES, P. et al. Mapa de infiltração do alto e médio Vale do Paraíba do Sul com base em elementos do meio físico e precipitação. Revista Ambiente \& Água, Taubaté, v. 3, n. 1, p. 26-42, 2008.

TASSINARI, C. C. G. Tectônica global. In: TEIXEIRA, W. et al. (Org.) Decifrando a Terra. São Paulo: Oficina de Textos, 2003. p. 97-112.

UNITED NATIONS MILLENNIUM DECLARATION. Nações Unidas: declaração do milénio. Lisbon: United Nations Information Centre, 2000. DPI/2163. Disponível em: <https://www.unric.org/html/portuguese/uninfo/DecdoMil.pdf>. Acesso em: 28 maio 2018.

VELOSO, J. J. O. A história de Cunha: 1600 - 2010: freguesia do Facão: a rota da exploração das minas e abastecimento de tropas. Cunha, SP: Centro de Cultura e Tradição de Cunha, Ed. JAC, 2010.

VIEIRA, I. Estrada aberta em Paraty pode ser embargada. Agência Brasil, Rio de Janeiro, 25 mar. 2016. Notícia. Disponível em: <http://agenciabrasil.ebc.com.br/geral/noticia/201603/estrada-aberta-em-paraty-pode-ser-embargada>. Acesso em: 6 jul. 2017.

Recebido: julho de 2017. Aceito: maio de 2018. 